\title{
Supply-Chain Management Issues In The Oil And Gas Industry
}

Christopher M. Chima, (E-mail: cchima@csudh.edu), California State University, Dominguez Hills

\begin{abstract}
The oil and gas industry is involved in a global supply-chain that includes domestic and international transportation, ordering and inventory visibility and control, materials handling, import/export facilitation and information technology. Thus, the industry offers a classic model for implementing supply-chain management techniques. In a supply-chain, a company is linked to its upstream suppliers and downstream distributors as materials, information, and capital flow through the supply-chain. The purpose of this paper is to investigate the role of supply-chain management in the oil and gas industry. This paper also discusses the application of the Uniform Commercial Code (UCC) to supply-chain management issues. Then, several strategies are examined for improving supply-chains in the oil and gas industry. Finally, two case studies are introduced to show how improving supply-chain logistics in the oil and gas industry can improve efficiency and the bottom line.
\end{abstract}

\section{INTRODUCTION}

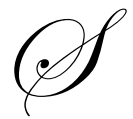

upply- chain management (SCM) can be defined as the configuration, coordination and continuous improvement of a sequentially organized set of operations. The goal of supply- chain management is to provide maximum customer service at the lowest cost possible. A customer is anyone who uses the output of a process. Therefore, the customer's customer is important to any organization that is focused on customer service. In a supply-chain, a company will link to its suppliers upstream and to its distributors downstream in order to serve its customers. Usually, materials, information, capital, labor, technology, financial assets and other resources flow through the supply-chain. Since the goal of the firm is to maximize profits, the firm must maximize benefits and minimize costs along the supply-chain. The firm must weigh the benefits versus the costs of each decision it makes along its supply-chain. Supply-chain management is therefore an extension of the focus on customer service.

Today, there are more opportunities for coordinating activities across a supply-chain even in such complex operations as oil ad gas, because of improving information systems and communication technologies. Integrating operations management with other functions of the operation allows all functions to be involved in the supply-chain management decisions.

Historically, the ownership of business supply-chains has always been highly concentrated. Typically, it is common to manage high-tech operations separately from low-tech operations and capital intensive operations from labor intensive operations. It is also common to manage by considering scale economies. Thus, it is common to separate operations that produce standardized products and services in large quantities from those that produce a great variety of customized products in smaller quantities. In focusing on operations, it is desirable for a business in a supply-chain to have a homogeneous mix of products and customers.

In recent times, there have been concerns and many have argued that the oil and gas industry may have entered an era of very scarce resources. In reality however, the resources are not the cause of supply constraints, given the enormous potential still available including, currently known and booked reserves, the increasing scope for recovery from existing fields with new technologies, further potential discoveries, and the new frontier of vast oil sands and oil shale reserves that are in the money at today's prices. 
Essentially, according to a good majority of the industry's research, we have enough resources left to sustain current production levels for at least the next 50 years. Therefore, the main challenge facing the oil and gas industry is not the availability of oil and gas resources, but putting these reserves into production and delivering the final products to consumers at the minimum cost possible. Thus, a solid supply-chain management program will enhance this goal.

\section{SUPPLY-CHAIN LINK IN THE OIL AND GAS INDUSTRY}

$$
\text { Exploration } \rightarrow \text { Production } \rightarrow \text { Refining } \rightarrow \text { Marketing } \rightarrow \text { Consumer }
$$

The links shown above represent the major supply-chain links in the oil and gas industry. The links represent the interface between companies and materials that flow through the supply-chain. As long as oil companies have needed a phalanx of vendors to keep their systems continuously re-supplied, there has been a supply-chain. Within each stage there are many operations. For example, exploration includes seismic, geophysical and geological operations, while production operations include drilling, reservoir, production, and facilities engineering. Refining is a complex operation and its output is the input to marketing. Marketing includes the retail sale of gasoline, engine oil and other refined products. Each stage of the link can be a separate company or a unit of an integrated firm. The common issue along the links in the oil and gas industry supply-chain is economics; weighing benefits versus costs along the chain.

Very few industries can benefit from maximizing supply-chain efficiencies more than the oil and gas companies. In this industry, the types of shipments made vary widely from gloves to pipes, valves, cranes, chemicals, cement, steel, and drilling rigs, just to mention a few. In addition, very few industries require this immense array of supplies to be moved daily and frequently in large quantities domestically, globally, onshore and offshore. In exploration and production, most of the work and activities are repetitive. The companies drill a lot of oil and gas wells every year. A drilling contractor is required and as many as 45 or more different services are required to drill and complete each well.

In the oil and gas industry, almost all significant and important operations are planned in advance. Thus, the whole process can be massaged and fine-tuned into a high performance money making machine. The goal of supplychain management is to provide maximum customer service at the lowest possible cost. In the industry supply-chain link, exploration operations create value through seismic analysis and identifying prospects. Production operations become the customers that use the output of exploration. In like manner, refining is the customer of production while marketing is the customer of refining and the consumer of refined products such as gasoline is the ultimate customer.

There is a need to ensure that each company or operator along the supply-chain can respond quickly to the exact material needs of its customers, protect itself from problems with suppliers and buffer its operations from the demand and supply uncertainty it faces. For oil and gas companies, the profit margin can be greatly enhanced if the companies manage their purchasing dollars throughout the entire supply-chain.

One of the weaknesses of a supply-chain is that each company is likely to act in its best interests to optimize its profit. The goal of satisfying the ultimate customer is easily lost and opportunities that could arise from some coordination of decisions across stages of the supply-chain could also be lost. If suppliers could be made more reliable, there would be less need for inventories of raw materials, quality inspection systems, rework, and other nonvalue adding activities, resulting in lean production.

Tubes and tubular goods are among the important goods supplied to the oil and gas industry on a daily basis. These goods are very crucial and form part of the supply-chain link. The supply-chain in tubular goods is the process through which oil field tubular goods such as pipes, tubing, and casing are ordered, manufactured, transported, stored, prepared, and then delivered to the website for installation into a well. Managing this part of the supply-chain can be both an operational and logistics nightmare for most oil and gas companies. Delays in the arrival of pipes, casing, tubing, and other accessories, can result in extensive rig downtime and consequently high operating costs. 
In the exploration and production sectors of the oil industry, the product is exactly the same for all competing firms: oil and gas with very narrow product differentiation. Consequently, many of these firms cannot differentiate themselves from one another by introducing an exciting new product. Thus, exploration and production companies can only differentiate themselves based on the ability to economically find and produce oil and gas more efficiently than their competitors. So even though exploration and production companies are unique in many respects, a differentiating factor can lie in the ability to adapt a sound supply-chain management program.

\section{MANAGEMENT DECISIONS}

As defined earlier, supply-chain management involves configuration, coordination and improvement. There are issues to be considered in each case.

Configuration involves the following questions:

- $\quad$ what product-service bundle to produce

- what portions of the bundle to produce in house and what portion to purchase from others

- facility capacity

- location of facilities

- $\quad$ type of technology to adapt

- $\quad$ handling communications between suppliers and customers

- $\quad$ standards expected of customers and suppliers

Coordination from the perspective of each company involves the following issues:

- $\quad$ ensuring supplier effectiveness in cost, timeliness and quality

- $\quad$ setting appropriate targets for inventory, capacity, and lead time

- $\quad$ monitoring demand and supply conditions

- $\quad$ communicating market and performance results to customers and suppliers.

Improvement of the supply chain requires continuous evaluation and involves changing as required, the configuration and/or the approach to coordination in order to enhance the performance of the overall chain. It has been suggested that demand variability amplification in a supply-chain is problematic, but can be dampened by operating the supply-chain more coherently by using information sharing and lead-time reduction. The effect of such a move is simply to reduce costs along the chain.

Operations researchers had traditionally used analytical approaches focusing on how to improve the efficiency of the individual entities along a supply-chain instead of improving the performance of the entire supply chain. The choice as to which to focus on is an economic decision hinging on which approach provides maximum benefits at minimum cost. The question here then is whether the sum of the parts is greater than the whole.

Since the goal of supply-chain management is to provide maximum customer service at the lowest possible cost, it has also been advocated that the supply-chain be managed as an integrated and coordinated system (Forrester: $1958,1961)$. This would further reduce costs by eliminating unnecessary uses or requirements which are loads on the chain. Loads are costs and integrating the system reduces loads, hence, costs.

\section{VERTICAL INTEGRATION}

Recent developments highlight the need to manage a company's supply-chain in an integrated and cohesive manner. These developments include the increased demand for better and faster customer service, globalization of the oil and gas business, competition, and the availability of information technology to facilitate information exchange. Therefore, integration and cohesiveness will reduce costs if it leads to a more efficient system. 
In the oil and gas industry recent developments also prevail. Depleting the existing oil and gas assets is forcing many companies to find new oil and gas in new frontiers. These new frontiers are often found in more challenging environments, thereby forcing firms to drill deeper and further offshore. These recent developments have increased not only the technical and operational difficulties, but also the costs and risks associated with the development of new assets.

In response to these changes, many forward-thinking oil companies are moving away from being just oil drilling companies to seeing themselves as reservoir development and resource management companies. Supporting this necessary and important shift in strategy requires or calls for a need to visualize, link, and manage the acquisition, exploration, and production functions of an oil company in a more integrated, cohesive, and balanced manner.

A supply-chain configuration strategy for oil and gas companies involves the development of boundaries and parameters that determines the relationships within its chain of customers and suppliers. Acquisition, exploration and production functions are strongly interrelated, yet traditionally; they are usually conceptualized and managed as independent areas.

The question of what functions to perform in-house by a firm and what functions to contract out is associated with vertical integration decisions in the oil and gas industry. Vertical integration is the joining of one firm with another to which it either sells an output or from which it buys an input. Vertical integration works very well in an industry such as the oil and gas industry where the output from one firm is the input to the other firm along the supplychain. As illustrated above, the output of exploration is the input to production. The output of production is the input to the refinery, while the output of the refinery is the input to marketing. Therefore, the oil and gas industry provides an excellent avenue for vertical integration.

If input materials are not related, unique, or exclusive to the firm's current business focus, then vertical integration is not necessary. However, if producing the input material is in line with the firm's current focus, then; vertical integration will be proper only if internal suppliers are more competitive than external suppliers. For example, an oil and gas production company may perform its own seismic and exploration work, or merge with a seismic firm only if its internal supplier, the seismic firm, is more competitive than external suppliers. In the same manner, if a firm holds the exclusive rights to an input then vertical integration is worth considering.

Sometimes, vertical integration may still be considered even when a good or service is not in line with the firm's current business focus. In such cases, vertical integration can be based on the long-term economic value of the supplier's business. For example, ARCO might get into the business of producing candies or sodas for its gas stations with mini-markets only if such a business promises to be profitable in the long-run. Typically, an input that is both required by a firm and is consistent with its current business focus gives the strongest incentive for vertical integration.

A firm can integrate forward or backwards. While forward vertical integration decisions dictate what a firm can sell versus what it can keep for future operations, backward vertical integration decisions dictate what a firm can make and what it should buy. These forward and backward linkage decisions set the boundaries for each firm's value adding systems while the goal of the firm still is to maximize benefits and minimize costs so as to maximize the profits and returns to shareholders.

The theory of comparative advantage can be applied in analyzing these questions of what functions to perform in-house and what functions to contract out. Comparative advantage can be defined as the ability of a firm to produce a good or service with a smaller sacrifice of alternative goods than the rest of its competitors. The sacrifice of alternative goods defines the opportunity cost, which is the true cost of producing a good or service measured in terms of other goods or services that must be given up to obtain it. Thus, comparative advantage is the ability to produce a good or service at a lower opportunity cost than someone else or other producers. Using this principle then, a firm will perform in-house, those functions for which it incurs the minimum opportunity cost and contract out those functions in which it lacks the minimum opportunity cost. 
Fully integrated oil companies own all the value adding steps pertaining to the production of their productservice bundles. Since for a vertically integrated firm the whole value chain eventually ends up on one consolidated income statement, one negative aspect of vertical integration is the increased exposure to financial risk associated with the business cycle of growth and recessions.

When a firm controls most of the assets in a supply-chain, it bears most of the burden of the economic problems associated with the slow sales period of the chain. For an integrated oil and gas company, a slow sales period could result from a period of lower crude oil prices. When many firms share the supply-chain, economic burdens during downturns can spread amongst these firms.

Other disadvantages of vertical integration may include a loss of expertise associated with the consolidation of management and operations, failure to recognize external market opportunities because of internal market, and a loss of competitiveness resulting from the secure internal market.

On the other hand, there are many benefits to vertical integration. These benefits include greater control over product quality, grater coordination of operations along the value chain, access to new technologies, and other intelligence of strategic importance, plus the potential for larger total profit margins. Ultimately, by weighing benefits versus costs, a firm can determine its ideal level of vertical integration. An oil and gas company that chooses not to integrate vertically can try to gain some of the benefits of vertical integration by assigning some amount of energy and resources to the development of long-term relationships with their customers and suppliers.

\section{OUTSOURCING}

As an alternative to vertical integration, outsourcing is the process of contracting with third parties to furnish some aspects of the product-service bundle. Outsourcing benefit's a firm in different ways. First, it provides a firm the opportunity to focus on what it does best - its core competences. Next, it allows the firm to add capacity without added overhead and fixed costs. Finally, outsourcing fosters market agility and corporate growth. Thus, it allows a firm to grow without undertaking large capital investments and in addition provides more flexibility during periods of economic downturns. Outsourcing has become one factor in creating a global supply-chain management.

Outsourcing may provide much better quality and supply-chain performance. The big question is "what should the company outsource?" The big answer appears to be anything that can be done more effectively by another provider.

\section{STRATEGIES FOR SUPPLY-CHAIN COORDINATION}

Supply-chain management requires an oil and gas company to integrate its decisions with those made within its chain of customers and suppliers. This process involves relationship management by the company. Both customer relations and supplier relations are key to effective coordination of supply-chains. Often, the interaction between suppliers and their customers are adversarial in nature, based on a negotiated contract that spells out all the terms and conditions by which all parties are required to comply. Instead, a firm can create long-term strategic relationships with their suppliers. In most cases, it is a collaboration process between the oil and gas operating company and its suppliers.

Sole sourcing is a practice whereby a company commits to buy all of a particular type of its services or goods from one vendor. This is also known as a requirements contract. In exchange, the vendor becomes a partner in the design of new product-service bundles. Vendor expertise and knowledge can be shared and leveraged for product process improvements. Therefore, the costs of negotiating and administering contracts can be significantly reduced.

However, it is important to note here that liability issues can arise from such arrangements. If the vendor is a partner in new product design and there is a design or manufacturing defect which causes harm or injury, who will be liable for the harm done, the firm or the supplier-partner? Such liability issues can be part of the initial discussions between a firm and its partner-supplier. 
Ultimately, such arrangements or relationships require supply chain partners to trust each other and conduct their business with integrity. Without the ability to trust supply-chain partners, such a strategy as discussed here would be very difficult.

Relationship management is not all about customers dictating requirements for suppliers. It is a two way traffic. Rather than following a sales-intensive strategy, suppliers may benefit from relationship marketing techniques. Instead of focusing entirely on negotiating the optimal conditions for individual orders or contracts, suppliers need to demonstrate their strength and capabilities to gain the trust of their customers.

\section{THE UNIFORM COMMERCIAL CODE (UCC) AND SUPPLY-CHAIN MANAGEMENT.}

Along the oil and gas industry supply-chain, the UCC governs the terms dealing with the sales of goods. Article 2 of the UCC applies to contracts that are primarily for sales of goods. It applies to suppliers of tangible goods to the oil and gas companies. The UCC not only applies to merchants, but also to private parties, in the sales of goods. The UCC does not apply to services.

Under the UCC, there are delivery obligations for the seller of goods when no place of delivery has been agreed upon. Absent any prior agreement as to the place of delivery, then the place of delivery is the seller's place of business. However, if both the buyer and seller know that the goods are at a particular place or location, then that place is the place of delivery.

Where there is an agreement as to place of delivery by a common carrier, then, there are two possibilities under the seller's delivery obligation.

With shipment contracts, the seller will complete its delivery obligation when it gets the goods to the common carrier, makes reasonable arrangements for delivery, and notifies the buyer. Otherwise, delivery is not complete.

In destination contracts, the seller's delivery obligation is not complete until the goods arrive where the buyer is. Sometimes, it may be difficult to determine whether a delivery contract is shipment or destination. Where there is free-on-board (FOB) followed by city where the seller is or the place where the goods are, then it is a shipment contract. However, where you have FOB followed by any other city, there is a destination contract.

Risk of loss issues may also arise if the goods are damaged or destroyed before the buyer receives the goods and neither party (buyer or seller) is to blame. Risk of loss can be determined by agreement of the parties. If the risk of loss is on the buyer, then the buyer has to pay the full contract price for the damaged or lost goods. On the other hand, if the seller has the risk of loss, then there is no obligation on the buyer, but a possible liability on the seller for nondelivery of the goods. If there is a breach of contract, then the breaching party is liable for any uninsured losses.

If delivery is by a common carrier other than the seller, then the risk of loss shifts from the seller to the buyer at the time the seller completes its delivery obligation, described above. Otherwise, where there is no agreement, no breach, and no delivery by a common carrier, the risk of loss shifts from a merchant-seller to the buyer upon the buyer's "receipt" of the goods. For a non-merchant seller, the risk of loss shifts to the buyer when the seller "tenders" the goods.

\section{IMPROVING SUPPLY-CHAIN LINKS IN THE OIL AND GAS INDUSTRY}

Once a supply-chain has been established, and coordination mechanisms are in place, it can still be improved. Today, oil and gas companies are looking for new ways of reducing total operating costs and improving efficiency and profits. In many cases, it is possible for the ideal configuration to change over time, due to changes in technology and consumer preferences. In some other cases, technology may allow several mechanisms for configuration across the supply-chain. Generally, oil and gas companies should view their supply-chain configuration and coordination systems as worthy of improvement. Making necessary improvements over time allows the firm to gain competitive 
advantages in the marketplace. A firm, believing its supply-chain has been optimized, can easily loose competitive advantages by being resistant to changes that might lead to improvements. The following eight strategies are recommended for improving oil and gas industry supply-chains.

\section{Segment Customers Based Upon Service Needs}

Different customers have different and sometimes unique requirements and meeting these requirements may necessitate different approaches to supply-chain configuration and coordination. Overall performance can be improved through effective matching of what is produced, when it is produced and the quantities to be produced to the specific customer requirement. To do this will require a certain level of marketing research, operational flexibility and sophisticated cost accounting.

\section{Customize Your Logistics Network}

Logistics is a major part of a supply-chain. In addition to producing or providing the good or service a customer wants, it is very important to deliver the product-service bundle in the quantities and particularly, timing requirements set by the customer. Improvement of the supply-chain implies customization of the logistics network.

For example, the entire logistics network in an oil and gas company can be strengthened when geologists, geophysicists, drillers, production engineers, reservoir managers, facilities engineers, economic evaluators, financial analysts, marketing experts, and government representatives come together to evaluate the technical and economic feasibility of an oil field development opportunity. By including the economic and financial aspects, many potential deal breakers can be discovered very early in the process. Such deal breakers can include potential losses from foreign exchange risks, taxes, and royalty issues. Having government officials participate early in the technical process helps in addressing some of these challenges.

There are logistical challenges that are shared by both the operating company and its suppliers to ensure that the right services, along with the right technical configurations are delivered at the well site at the appropriate time.

\section{Watch for Market Signals and Plan Accordingly}

This process involves the reversal of the traditional practice of depending on demand forecasts created independently by various business segments of the supply-chain. Planning based on such forecasts often result to material and capacity imbalances and a bullwhip effect. A bullwhip effect is the tendency of small variations in demand to become larger as their implications are transmitted backward through the supply-chain.

Demand variability amplification in a supply-chain is a big problem. Demand variability also increases as demand travels upstream in a supply-chain. This amplification of demand fluctuations from downstream to upstream in a supply-chain is the bullwhip effect. Dynamics and instability in schedules are constantly amplified from downstream to upstream in a supply-chain and should be controlled or dampened. Without this controlling or dampening measure, instability will result to larger costs. Variability also comes from changes and updates of the demand forecasts.

\section{Form Partnerships To Enhance Supply-Chains}

As was shown earlier, relationships management is a two-way traffic. The oil and gas industry is involved in a global supply-chain that involves domestic and international transportation, value-chain strategic warehouse management, order and inventory visibility and control, materials handling, import/export facilitation, and information technology. This means in effect that the shipper and the oil company are jointly and mutually involved and intertwined with each other, end-to-end in transportation management from the moment an order is placed by the vendor to the day it is unloaded from the supply basket on the offshore platform. 
Depending on the oil and gas company's discretion, the shipper's involvement can be as little or as in-depth as assisting the oil company in coordinating with vendors as to when supplies will be available, to the actual bringing of the materials to a staging center and handling the rest of the transportation cycle from there.

\section{Apply Strategic Sourcing}

Strategic sourcing implies that suppliers who have consistently demonstrated superior performance deserve a favorable status, including customer loyalty and preferential treatment. Therefore, one method for improving a supplychain is to select an excellent corps of suppliers.

One of the most important considerations in supply-chain management for the oil and gas industry is that in the reality of everyday life in this industry, there is no just-in-time (JIT) in exploration and production. In particular, supplying an offshore platform is close to supplying a small city. Thus, there is a need for continually forecasting what will be needed beyond daily routine and reoccurring supplies.

For example, an oil company can have 12 offshore platforms and over 400 vendors and suppliers that service these platforms. In supply-chain management, these vendors and suppliers can be coordinated into one location, which in effect becomes a consolidation and expediting location. Thus, eliminating a lot of waste and costs.

\section{Adapt a Supply-Chain Wide Technology Strategy}

Difficulties can arise when oil and gas companies make technology decisions independently along their supply-chains. Thus, their information systems are neither coordinated nor compatible, and information is not readily shared back and forth along the supply-chain.

As it is becoming more difficult and more challenging to find easily accessible new oil and gas discoveries while the existing fields are being depleted, oil and gas companies are being forced to take a more integrated approach to exploration, production, refining and marketing operations. Thus, one way of crossing this divide today is by adopting better and improved secondary and tertiary recovery technologies across the entire supply-chain.

With modern information systems technologies, piecemeal assembly of components will not create an optimal management experience. The oil and gas industry requires a fundamental work-process change in order to accommodate the growing virtualization of a multinational business. Exploration and production will benefit from simplifying and streamlining data management and access, interlocking the experiences of regionally disparate workers, saturating investments and operational decisions. As the industry undergoes continued and accelerated consolidation, the need for a flexible, extensible, scalable, and adaptable system is more important than ever along a firm's supply-chain.

Adapting a supply-chain wide technology strategy can also result in every user of the system along the chain seeing a single file system, can access all computational servers with high speed data access, can connect to real-time high speed visualization, and can participate in realistic collaboration, and be provided instant service irrespective of the user's location or desktop device. This also allows the system administrators to manage the enterprise from anywhere.

In addition, such functional factors as business-process modeling, automated notification, data access and sharing, and visualization should be available to the supplier just as it is to employees and other interested parties. This step is crucial in order to maximize the potential benefits of the collaboration between an oil and gas company and its supplier organizations. This results to the actual extension of the operating firm when it comes to planning and executing complex services. 


\section{Develop Channel Spanning Performance Measures}

Oil and gas companies tend to hire individual decision makers, but a measurement of supply-chain-wide performance will provide incentives for supply-chain improvement. If localized decision making is perpetuated across the chain, then, inefficiencies associated with it will not be eliminated.

\section{Adapt or Create Operational Innovation}

Operational innovation has been defined as "the invention of news ways of doing work" (Close, 2006). This can also be thought of a process of inventing new ways of solving old problems. Traditionally, many oil and gas companies grow through the process of diversification of businesses, mergers, and acquisitions. In addition to these methods, an oil and gas company can grow and achieve superior profitability through operational innovation.

Operational innovation includes a supply-chain management program encompassing the integration and innovation of the process for engaging and communicating with suppliers, and doing so in a way that competitors cannot duplicate or replicate. This requires flexibility along the supply-chain, reflecting a completely new way of interacting with suppliers, a revolutionary rather than evolutionary behavior along the supply-chain.

Furthermore, operational innovation includes coming up with entirely brand new ways of developing new products, providing customer service, filling orders, or performing any tasks along the supply-chain that adds value to the enterprise. Therefore, the objective of applying operational innovation along the supply-chain is to discover new ways of working by examining and optimizing core business links.

\section{CASE STUDIES}

Some case studies can be found in the literature on how a fully integrated supply-chain management program can be used by an oil and gas company to improve operational efficiency, resulting to lower cost per well. Hoffman (2004) described two field applications of the fully integrated supply-chain management process.

The ConocoPhillips Ekofisk offshore platform is located nearly 200 miles off the Norwegian coast in the central part of the North Sea. The horizontal position of the last 5,000 ft of the X50 well (the well numbered or labeled X50) posed a significant challenge for the supply-chain manager.

Furthermore, the severe weather conditions that exist in the area made supply delivery and operations particularly difficult. By using a Just-in-time (JIT) installed colum services provider that coordinated tubular-goods planning, ordering, preparation, logistics, and installation, ConocoPhillips was able to complete the well and put it on stream in 30 days.

ConocoPhillips also took the same approach at its largest offshore discovery in China. This was in the Penglai 19-3 oil field in the Bohai Bay. In this case, one of the main challenges was the need for a regular supply of prepared casing in two different sizes in order to satisfy the fast moving batch drilling activity that was taking place.

By training and coordinating the workforce and the activities of several local service providers, the supplychain manager enabled ConocoPhillips to accomplish the core logistical requirements for the project.

In both cases, efficient management of the supply-chain was estimated to have achieved savings of about $25 \%$ in procurement and installation costs. 


\section{REFERENCES}

1. $\quad$ Bahree, B. Investment by Oil Industry Stalls. The Wall Street Journal. November 8, 2006. A11.

2. Bartling, B. The Catalyst to Virtualization: Virtual Consolidation. Journal of Petroleum Technology. October 2003. 33.

3. Bento, J. Supply-Chain Logistics Reduce Costs. Journal of Petroleum Technology. August, 2003. 29

4. Boyles, W. and Melvin, M. Microeconomics, $6^{\text {th }}$ Ed. Houghton Mifflin Company, 2005.

5. Bozon, I. Uncertainty and Volatility in Today's Energy System: Stability, Security, and Sustainability Through Mutual Interdependence. Journal of Petroleum Technology. March, 2006. 47

6. Close, D. Building the High-Performance E \& P Company. Journal of Petroleum Technology. September, 2006. 66

7. Chu, E. Managing Supply Chains: Lessons From Simulation Studies. California Journal of Operations Management. Vol. II, No. 1, 2004.

8. $\quad$ Epstein, D. G. National Contracts. Teaching Hypotheticals. Barbri Bar Review. CICW, 2006.

9. Forrester, J.W. Industrial Dynamics: A Major Breakthrough for Decision Makers. Harvard Business Review, 26(4), 1958. 37-66.

10. Forrester, J.W. Industrial Dynamics. MIT Press, Cambridge, 1961

11. Frank, R. H. Microeconomics and Behavior, $6^{\text {th }}$ Ed. McGraw-Hill Irwin, 2006

12. Gold, R. Going Deep. Energy Companies Are Finding New Opportunities in Old Rocks. The Wall Street Journal. October 16, 2006. R8

13. Hanna, M. O. and Newman, W. R. Integrated Operations Management - Adding Value for Customers. Prentice Hall, 2001.

14. Hoffman, B. Integrated Tubular-Supply-Chain Management Reduces Cost. Journal of Petroleum Technology. October 2004. 40-41

15. Mansfield, E. Managerial Economics and Operations Research-Techniques, Applications, cases, $4^{\text {th }}$ Ed. W. W. Norton \& Company, 1980.

16. Miller, R, M. Economics Today - The Micro View, $12^{\text {th }}$ Ed. Pearson Addison Wesley, 2004.

17. Rabbino, H., Dunham, C. and Ritchie-Dunham, J. Optimizing the Organizational Design of a Typical Upstream Exploration and Production Company. Journal of Petroleum Technology. February, 2004. 30

18. Sharp, A. M., Register, C. A. and Grimes, P. W. Economics of Social Issues, $13^{\text {th }}$ Ed. McGraw-Hill Irwin, 2006. 